\title{
Design thinking: a Fruitful Concept for Strategic Enterprise Management
}

\author{
Jia Jiao ${ }^{1, a}$, Rong Zhang ${ }^{1, b}$ \\ ${ }^{1}$ School of Mechanical Engineering and Automation, Beihang University, Beijing 100191, China. \\ ajjialuck@163.com, brongzhangb507@163.com,
}

Keywords: Design thinking; Strategic Enterprise Management; Innovation

\begin{abstract}
In order to achieve a breakthrough innovation and obtain the leading position of market, design thinking is an important strategic concept for strategic enterprise management. In this paper, it analyzes the characteristics and value assessment of design thinking. Through research on the reason why strategic enterprise management needs design thinking, it summarizes the application aspect of design thinking in strategic enterprise management. Strategy enterprise management based on design thinking establishes design as the leading of organization ecology system, and creates the innovative design inside the organization. Through using prototype design tool and design flow of rapid iteration, design thinking breaks the constraint and realizes the business sustainable development.
\end{abstract}

\section{Introduction}

Design thinking is the process of transforming managers' perceiving, rational analysis, along with technical, commercial, cultural, and many other factors, into customer value and market opportunities. The understanding of design is changing from the original manufacturing auxiliary function to the new level of enterprise systematic design. Over the past decade, some leading companies achieve sustainable competitive success by taking advantage of design thinking, such as Apple, MUJI, IKEA, etc. The goal of design thinking is to make consumers, designers and businessman participate in a unified process, which is applied to products, services, and business experience. The application of design thinking in areas of strategic enterprise management has a significant influence.

\section{Design thinking}

Design thinking is a user-centered innovation process and an effective creative thinking to direct design activities. It has the reliability of analytical thinking and creativity of intuition thinking. Design thinking in products creation can help people communicate friendly with products. The success of the communication will directly affect the economic benefits of enterprises, and change people's lifestyle. While practice has proven that design thinking is a promising approach for companies, looking at it systematically and with scientific rigor is a rather new endeavor[1].

Characteristics of design thinking.

Observation: Through close observation of people to obtain in-depth information, design thinking can find those underlying requirements. For example, researchers can create a more efficient checkout system according to the habit of shoppers in the checkout line. The system can ensure consumers go through the cashier quickly and take full use of consumers' impulse purchases at the last minute.

Cooperation: Design thinking emphasizes cooperation among all interested parties. In different stages of innovation process, interested parties are invited to work with designers, researchers, and developers to dig requirements, find solutions, and make assessments. This participatory design advocates the user further integrated into the design process, cultivate the user's host awareness, inspire and mobilize their enthusiasm and initiative.

Idea visualization: By intuitive means of graph, experiment and rapid prototyping, design thinking makes communication clearly and effectively. Besides it will get effective feedbacks from users for improvement timely. Through the process of rapid experiment, feedback and improvement, enterprise can get high added value with low investment. 
Synthesis: Design thinking is synthesis thinking. It includes reverse and forward thinking, divergent and convergent thinking, jump thinking, and so on. Through effective switch between these different thinking ways, design thinking makes design activities creative and fruitful.

\section{Value of design thinking.}

Design activity is not a simple individual behavior or a group's behavior. Design is closely related to the government's macro decision-making. It has gradually become an important part of social public events, and penetrated into all aspects of social and economic life. The essence of "design" is to restructure knowledge structure and industrial chain, as well as to integrate resources and recreate mechanism of industry. In the long run, design leads human society to healthy, reasonable and sustainable development.

Design thinking plays an important role in the sustainable development. In the activities of extending the product life-cycle, reduce repeat of the same kind of production, save energy and resources for mankind, design thinking should spare no effort.

\section{Strategic Enterprise Management needs Design Thinking}

A management survey among 1500 American senior managers carried out by Thomas Lockwood, Neutron and Stanford University summarizes the top ten questions concerned by businessman. In the top ten questions, besides routine profits and growth, there is a unified strategy and customer experience, ecological sustainable development challenges, social responsibility and so on[2].

Originally the competition is the financing channels, technology property rights, legal protection, distribution network, and so on, but these are soon collapsed. In the complex economic environment, the original successful model cannot put the enterprise forward. There needs to be a new model to win this business war. In the face of solving these intricate problems and challenges, managers can take advantage of design thinking to find the answer. The reasons are concluded as below.

\section{Technology innovation.}

The technology is profoundly changing the way business works. Technology is the process and tools of materializing design thinking. On the one hand, design thinking can better integrate the existing technology to achieve the most efficient application. In the strategy management, it can maximize the user experience and realize product innovation from the perspective of the users.

On the other hand, design thinking provides development direction for technical application and further promotes the scientific research innovation. Design thinking is a kind of dynamic selective thinking based on logical thinking and image thinking. In the scientific research, it can effectively assist researchers for logic analysis, experimental trial, and preferential selection behavior. Through risk assessment, market analysis, and application innovation, scientific research and technology can be easily transformed to products. It adjusts the way we observe the world, and provide new possibilities for the development from another dimension. Such as a few of enterprises are researching on "concept design" for strategic reserves.

\section{Market expectations are highest than ever.}

In numerous goods and services, consumers expect to have more creative products and services. In the beginning of the reform and open policy, our country was in the form of foundry. It caused serious imitation and the lack of innovation. This restricted the development and progress of our country's product design[3].With comprehensive transformation from "made in China" to "designed in China", design is changing people's lifestyle along with the changing market demand.

As American most creative enterprise, Apple creates revolutionary iPod, iPhone, and iPad based on demand innovation and overturns the lifestyle of people. Take the mobile phones for example, through analyzing of the development history of mobile phones from two dimensions of user experience and technology content, we can conclude that the development of the mobile phone shows roughly increase. So the foreseeable future development trend of mobile phone will be conducted in user experience and technology. 


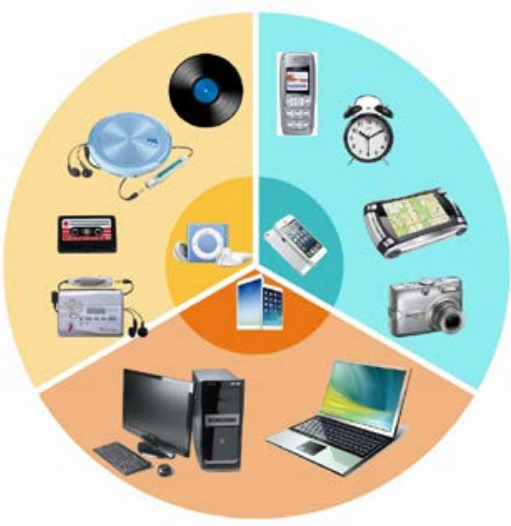

Fig. 1 Apple product innovation

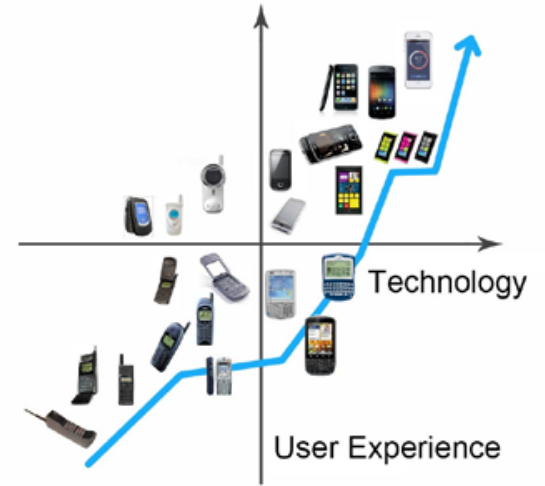

Fig.2 Mobile phone development analysis

\section{Globalization.}

Globalization is a challenge for enterprises to realize global business and brand. In the markets under different culture, user research is necessary to promote design strategy. Design thinking helps enterprise to rethink the product's relationship with social and economic structure and seek a new business model. "Innovators dilemma" is put forwarded by Christensen in 1997, which is that well-managed enterprise with strong ability to innovate may lose leader position due to it is unable to adapt to market changes[4-5]. The reason for this is that the enterprises focus too much on the mainstream market and consumers, while ignore new small markets with low input-output efficiency and high risk. So that they lose the best time to step in this market. At the same time, small businesses will achieve destructive innovation success in this part of the market. Market is uncertain and we can't get the solution from the market itself. But design thinking is based on the dimensions of human psychology and social culture. It studies the evolution of society, economy, arts and science and technology, so it successfully spans the problem of market uncertainty. Strategy management based on design thinking can provide new solutions for innovators dilemma. Through looking for the answer from a broader perspective, it can effectively break the deadlock and help enterprises realize global business and brand.

\section{The application of design thinking in Strategic Enterprise Management}

\section{Develop Emotional connection.}

Design thinking is a process of user-centered. It emphasizes to understand customers deeply. Connecting with customers and satisfying their emotional requirements are necessary. The application of design thinking in strategic enterprise management can make the enterprise pay close attention to the behavior of the target population, and excavate the requirements that users failed to fully express and describe.

For all brands in different fields, design thinking is the strong part of management strategy. Through perceiving emotional connection with customers and understanding the potential needs, enterprise can achieve breakthrough innovation from the essence of problem. Nike is a good example for this. Runners always have the desire to pursue better individual performance, realize personal goals, and share their passion with others. Nike deeply understand customers' requirements and make this kind of thinking into the Nike+. It inserts a chip in the unique-design running shoes. When you exercise, it will connect the running shoes to the iPod, measure runners' achievement, and connect to the runner's online community. Through this activity, market share of Nike increases to 61\%, and achieves a win-win with Apple. In the information and knowledge economy era, design is not only industrial product design, but also extended to service design, experience design and systematic design.

\section{Adjust design strategy and business strategy.}

In addition to the deep understanding of customer needs, the enterprise needs to format design-dominated ecological system in the internal organization. Through breaking all kinds of constraints and adopting iterative design, enterprise can form a sustainable business model of 
innovation. Design make the enterprise strategy into reality, so appropriate design can affect the effectiveness and internal adoption of strategy. The adjustment of business strategy includes design development plan, roadmap, brand promotion and so on. It is important to recognize that each activity and output in the organization depends on the design. For example, through analyzing how to pass the value of critical business more effectively to the target customer with design thinking, it can optimize acquisition channels of products and services for customers.

\section{Innovation.}

Innovation leads the difference between businesses, and design promotes innovation. Just like Marty Neumerier said in "The Designful Company" that all kinds of creativities have become the first drive engine for economic growth.

Different from traditional radical innovation based on technology push and value-added innovation based on market traction, design thinking is a new model in the field of strategy management innovation. The third industrial revolution based on information is accelerating the change of the market consumption structure. As the main part beside the usability consumption, cultural consumption is more and more get the attention of the society. It makes consumers pay more attention to the meaning of product besides function. According to this change, Verganti, an Italian scholar, proposed the third innovation----design-driven innovation[6], which promotes the innovation through the creation of the product meaning. Design-driven innovation starts from the basic needs, changes the basic understanding of products, and promotes the implementation of the innovation.

Design thinking emphasizes that managers query established reality and basic assumptions like a designer. In the complex market environment, the way of querying and reflection on the basic problem can often get surprise.

\section{Conclusion}

Today, we found that original successful mode has no longer adapted to the current social situation. There need to be better, faster, more effective method for organization adjustment in order to obtain leading position. Business strategy management based on design thinking establishes design as the leading of organization ecology system, and creates the innovative design inside the organization. It builds the business model around the target customer factors, and integrates the available resources with an open, cooperation, tolerance, enterprising attitude. Through using prototype design tool and design flow of rapid iteration, design thinking breaks the constraint and realize the business sustainable development.

\section{References}

[1] Stone, Terry, Lee. Managing the design process: concept development [M]. Beijing: The China youth press, 2012

[2] Lockwood, Thomas. Design thinking: integrating innovation, customer experience, and brand value[M]. Beijing: Electronic Industry Press, 2012.

[3] Design-driven economic chance — the rise and challenges of Chinese design industry[M]. Beijing: China Machine Press,2014.

[4] Chen Xuesong. The research on design-driven innovation mechanisms and design pattern evolutions [M].Beijing:China Social Science Press,2013.

[5] Christensen, C.M. The Innovator's Dilemma: when new technologies cause firms to fail [M]. New York: HARPER Collins publishers, 1997

[6] Verganti, Roberto. Design, Meanings, and Radical Innovation: A Meta-model and a Research Agenda [J]. Journal of Product Innovation Management, 2008, 25(5); 436-456. 